\title{
FREGE AND HUSSERL: THE ONTOLOGY OF REFERENCE
}

\section{BARRY SMITH}

The modern notion of object, encompassing not only external objects of the real world but also the abstract objects of, for example, mathematics, was introduced into philosophy with the invention by Bolzano ${ }^{1}$ and Frege 2 of existential quantification. Thus the notion has established its position in philosophy hand in hand with an approach to ontology, defended most persuasively by Quine, according to which object-status is relativised to membership in the domain of quantification of a formalised scientific theory. What has been little realised is that the theory of objects which is dictated by modern quantification theory can be given a non-relativistic foundation within traditional ontology, particularly as this has been developed by Husserl, Meinong, Ingarden and the Munich phenomenologists. ${ }^{3}$ This foundation rests on the possibility of drawing an ontological distinction between, on the one hand, 'object'-entities which can serve as the proper referents of our thinking acts, and on the other hand cognitive formations, such as meanings and concepts, in virtue of which those thinking acts are articulated. Thus an adequate ontology of objects will demand, as its complement, an adequate ontological theory of meaning-entities which is such that the opposition between these two domains can be brought into light.

Not every theory of meaning can serve as the basis for such an approach. For example, the theories put forward by Russell, Moore, and others at the beginning of this century would be unacceptable; for according to such theories the meaning of, say, a proper name, is identified with the object, which may be a real material object, denoted by the name. Thus the meaning of a sentence, which has among its constituents the meanings of proper names appearing in the sentence, becomes a pecular hybrid entity, which straddles the boundary between the transcendent world of objects and the domain of thought-formations. In contrast, the theory of meaning which Frege put forward in his paper "On Sense and Reference" suggests a much more promising account of the nature of meanings. This account may be viewed as founded on a principle of intellectual apartheid' according to which meanings, which are seen as depending only on the 'cognitive value' which relevant sentences have for a particular linguistic community, 4 can be distinguished as constituting what Frege called a 'realm of senses'.

Much work has to be done before we can justify the drawing of any ontological demarcation line between such a 'realm' and the realm of objects which is dictated by the modern theory of existential quantification. Difficulties arise, in particular, in virtue of the existence of contexts in which meanings or senses themselves seem to play the role of transcendent objects, by becoming referents, e.g. for the sentences of semantics itself. This is achieved by means of constructions of the form:-

'the sense of the expression "horse", or: 'the proposition expressed by the sentence "Caesar is a Roman general"'.

In fact for Frege every entity is a referent, or, more precisely, every entity is the potential referent of some suitably formed expression; and thus to acknowledge the status of senses as fullyfledged entities is already to acknowledge their status as referents. ${ }^{5}$ On the basis of such considerations some latter-day followers of Frege have wanted to conclude that any ontological interpretation of Fregean semantics must break down. Thiel, for example, argues that 'to be sign, sense or reference is only a role' which certain entities take on when they enter, in different ways, into semantic contexts, and that 'there is no justification for talking in semantics of "spheres", "realms", etc.' Indeed, Thiel holds 'the Fregean allowance of a participation of ontology in the doctrine of sense and reference for a completely unacceptable contamination'. 6

We hope to show that such conclusions are unwarranted. Certainly the simple sense-reference 
dichotomy has, as it stands, no ontological significance. But if we can show that there is a quite peculiar ontological structure which must be possessed by any entity which is to fulfil the function exercised by senses, then we shall be able to formulate an ontological interpretation of Frege's semantics, a first approximation to which may be expressed in terms of a distinction between

(i) entities which have the ontological structure which would make it possible, in appropriate conditions, for them to serve as senses,

(ii) 'objects' or 'ordinary referents' which do not possess such a structure.

Frege's own writings contain the germ of such an ontological interpretation of his semantic theory, for Frege frequently speaks, especially in his later works, of a 'realm of sense', a 'realm of reference', and even of a 'realm of word and sentence'. 7 Here the 'realm of sense' is viewed as forming a part of the realm of reference, that is to say, of the reality to which our thoughts are directed; but then, as Dummett recognises:

the realm of sense is a very special region of reality; its denizens are, so to speak, things of a very special sort.8

For an account of this 'special' nature of senses we must turn to Husserl, a philosopher who shared the problems and philosophical background of Frege. Husserl and Frege shared, in particular, an awareness of the inadequacy of the doctrine of psychologism which had achieved a position of dominance in Germany in the latter half of the 19th century. The problems which exercised the psychologists concerned, most importantly, the relations between objective configurations, such as linguistic meanings and logical laws, and the subjective experiences in which these are actualised. To give an example of a psychologistic 'solution' to one such problem: the broad conformity of our everyday thought and argument to the laws of logic is to be explained, psychologists might claim, by regarding these laws as statistically founded results of empirical psychology!
Frege, it seems, over-reacted to such views, and was led to conceive a mistrust for any epistemological approach to philosophy, even one which explicitly abandoned this kind of naive psychologism. Thus Frege's goal in the philosophy of mathematics became one of providing a nonepistemological foundation for mathematics, by demonstrating that the latter could be viewed as a branch of pure logic. Many technically important results were achieved by Frege in pursuit of this goal, but these have to be balanced against the ill-effects which Frege's approach to philosophy has had on the thought of his successors. For Frege's approach led him to ride roughshod over many phenomenological distinctions which had until his time been preserved, if not always in a pure state, by the philosophical tradition. ${ }^{9}$

Frege had adopted the view that, for one who takes an anti-psychologistic standpoint, it is impossible to give a clarification of the relations between objective configurations and subjective acts, since the latter, Frege held, fall outside the purview of any objective philosophical science. But Husserl saw that the anti-psychologistic position precisely demands a clarification of these relations. ${ }^{10}$ Thus he offered an epistemologically founded theory of $\operatorname{logic}^{11}$ which was of great explanatory power even in those areas where the psychologists had considered themselves particularly strong. Husserl saw the necessity to base the philosophy of logic and of meaning on a nonempirical analysis of the broad spectrum of mental acts, including speech acts, an analysis which would reveal the way in which objective formations can themselves serve as constituents in our subjective experience.

Husserl's theory of meaning finds its clearest expression in the first volume of his Logical Investigations, where it forms an indispensable part of the general theory of 'pure logic' put forward by Husserl as an alternative to the psychologistic theory. Husserl's reflections begin with an analysis of the nature of scientific theory in general; he points out that, although science is a psychological and an anthropological phenomenon, what makes science science 
is certainly not its psychology, nor any real context into which our acts of thought are fitted, but a certain objective or ideal interconnection which gives these acts a unitary objective relevance, and, in such unitary relevance, an ideal validity. [But] two meanings can be attached to this objective interconnection which ideally pervades scientific thought, and thus also to science as such: it can be understood as an interconnection of the things to which our thoughtexperiences (actual or possible) are intentionally directed, or, on the other hand, as an interconnection of truths in which this unity of things comes to count objectively as being what it is. These two things are given together $a$ priori, and are mutually inseparable.12

Thus 'the concepts which constitute the Idea of unified theory', the determination of which, Husserl argues, 13 constitutes the first task of pure logic, fall into two groups: one group consists of concepts which relate to things and to the interconnection of things, concepts such as object, state of affairs, plurality, relation, manifold of objects, and so on;14 and a second group consists of concepts which relate to truths and to the interconnections among truths, concepts such as concept, proposition, truth, the concepts of the 'elementary connective forms' (logical connectives), the concepts theory, theory-form, and so on. ${ }^{15}$

Husserl tells us that he is here putting forward a categorial distinction among concepts under which everything that appears in thought - that is, all entities - must be ordered, ${ }^{16}$ but in virtue of an insufficiently refined framework of formal ontology, Husserl failed to draw the ontological consequence of his conceptual distinction, as implying a parallel distinction on the side of the entities themselves. ${ }^{17}$ This distinction we shall recognise as a generalisation of the division between 'ordinary referents' and 'referents which may operate as senses' which we put forward above as a first approximation to an ontological interpretation of Frege's semantics. Entities, now, are seen as falling into two absolute and immutable categories, the category of object-in-general on the one hand and the category of meaning-ingeneral on the other. To the first category belong individual real objects such as molecules, human bodies, tables, etc., higher-order real objects such as swarms of bees, galaxies, and universities, and individual and higher-order ideal objects such as numbers, geometrical figures, sets, etc. This cate- gory includes also purely intentional objects ${ }^{18}$ such as Sherlock Holmes, Quetzalcoatl, perhaps even, say, large cardinals of Cantorean set theory. 19 Purely intentional objects are intersubjectively accessible as the objects of acts, even though they lack autonomous existence: they exist only in so far as they are intended as existing in particular networks of acts, e.g. on the part of readers of Victorian fiction or of Aztec worshippers. What gives such entities their intersubjective identity is, ultimately, their being bound up with autonomous objects, particularly of a linguistic nature 20 : actual copies of Conan Doyle's works or of Aztec scriptures. Besides autonomous and intentional objects proper, the category of object-in-general is to include also all those entities which are, with objects, dovetailed within the realm of ordinary reference; that is, it includes properties, relations, states of affairs, events, processes, etc.

The second category, the category of meanings on the other hand, contains individual and higherorder conceptual formations such as senses, concepts, and propositions, even whole theories, but identified, now, as articulated constituents of our cognitive experiences. For where Frege's senses had been correlated with linguistic expressions, 21 Husserlian 'senses' are correlated with acts: Husserl had seen that a remarkable generalisation of the three-term 'sign-sense-reference' theory of meaning could be made, that a 'sense' or determinate directedness to objects was common to all acts 'whether these are intertwined with expressing acts or not'.22 To come to a conception of this act-based 'sense'-factor - or 'noema' in Husserl's terms - we imagine a series of acts, all given as being directed to the same object from the same side and with the same characteristics, but differing in being acts of perception, of memory, of pure imagination, of involuntary hallucinations, etc. The acts differ also in that some are intuitively 'filled', 23 while others are empty intentions made, for example, on the basis of a linguistic description of the object. Then that which is common to all the acts cannot be anything which has the status of a referent for any of the acts: for unless we confine ourselves to 'veridical' acts of perception and of memory there can be no autonomous referent; and a Holmes-type intentional referent requires some kind of linguistic 
structure to guarantee its identical accessibility, but such a structure is absent except in the case of acts of language-guided imagination, e.g. within the context of reading fiction. What all the acts mentioned do have in common, however, is an intended referent qua intended - and it is this intended referent, as a common character exhibited by all the acts in question which was distinguished by Husserl as the noema or noematic sense of those acts. 24

What is the relation between Husserlian actbased senses and the objective linguistic meanings which form the basis of communication? First of all it must be recognised that an objective meaning is, in general, present only as the 'horizon' of any given act of ordinary linguistic experience in which it is meant: we select, as it were, from the objective meaning-stock of the expression only those constituents which are relevant or dominant for that context, other constituents and the objective meaning as a whole being only peripherally or emptily present. Further the given actualised meaning will be accompanied, in general, by alien 'filling', that is data imported from the perceptual and conceptual experience of the actualising subject. Nevertheless we can move more and more closely toward the given objective meaning by means of a (possibly communal) exercise of imaginative variation of context and of imported data, a process which I should like to call 'noematic abstraction'. Note that the result of such a process is not an abstract object, but an abstract noematic entity.

Given that such noematic abstraction is possible, and that all meaning-entities can at least in principle become the meanings, the noemata, of suitable formed acts or networks of acts, 25 it will be possible to introduce the predicate 'noematic' as a general term characterising all entities which belong to the category of meaning-in-general,26 and our categorial division can then be expressed as a division between noematic and non-noematic entities. Categorial, divisions of this broad type are drawn by analytic philosophers on the basis of different forms of identity criteria: the manner in which we re-identify, for example, a material body as 'the same again', is clearly distinct from the manner in which we re-identify mathematical objects such as numbers; hence, claim the analytic philosophers, these two sets of entities belong to different categories. ${ }^{27}$ The distinction which we wish to defend here, however, depends upon a contrast between modes of cognitive access: members of the category of objects are entities, access to which is by means of an intentional directedness of thought, where, in contrast, the proper mode of access to noematic entities is the mode of immediate actualisation: noemata are 'lived through'. $\$ 8$

In terms of the following diagram:

act, e.g. of

perception or ........... noema or sense ....... $>$ referent of memory

we can say that members of the category of objects must always lie at the end of an act (i.e. in the referent or 'target' position), where (to risk another metaphor) noematic entities may lie parallel to and thus be actualised in an act. 29 In particular, where we have an act of linguistically mediated reference, the linguistic meaning or sense involved will itself be actualised in the noema of the act of reference, somewhat as follows:

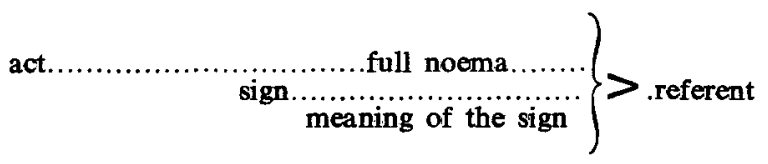

In connection with such diagrams we must note, first of all, that a noematic entity actualised in a given act is never the object (referent) of that act; rather it is transparent to the act, allowing access through and on to the referent (if there is one). ${ }^{30}$ But we note too that, despite this transparency, the noematic entity must possess also a particular determinate content, for we are directed to the referent in such a way that it is given in determinate aspects, from a given 'side', etc. Thus we see a whitish-grey patch against the sky as smoke rather than cloud; we see a distant stone structure as a tower rather than as a backless towerfacade; and so on for every act of reference, whether intuitive or symbolically mediated. This determinate content must itself be structured in such a way as to be given as the presentation of a referent. This is true even in those cases where there is no referent for the act but only a noema, that is only an intended referent qua intended; 
this intended referent is no more thereby also a referent than an intended insult ('Hegelian!') is thereby also an insult. A non-veridical act is, then, not an act in which the noema itself plays the role of referent: non-veridical acts are distinguished precisely by the absence of any referent. ${ }^{31}$

Objects, we said, must always lie at the end of an act, in contrast to noematic entities, the proper position of which is in parallel with an act. But it will by now be clear that given particular kinds of reflection and of abstract thought, noematic entities too may come to hold a referent position for a given act. Such an act will involve a new second-order noema of its own, as follows: 32

act of abstract. second-order noema...$>$ referent thought (original noematic entity)

One important species of such 'reference' to noematic entites is linguistically mediated reference based on constructions such as:

'Christ's vision on the cross',

'Pythagoras' theorem'

'the Gödelian argument'

'the General Theory of Relativity', and so on,

as well as more familiar examples such as the concept horse', etc. Such acts then conform to a much more complex/schema, in which the subject directs himself through a second-order noema associated with the sign in question.

Linguistic access to noemata is, of course, merely an empty or, as we shall now say 'improper' (uneigentlich) access-at-a-distance: here the matter is not radically different from the situation which prevails in the case of linguistic reference to objects. Entities of all kinds may, indeed, serve as the mediate targets for improper acts, as when, for example, we gain access-at-adistance to the tallest man in Smolensk, or to the central point of the Sun. But in the case of mundane objects we accept (and are justified in accepting) such linguistic access as an adequate surrogate for intuitive or fulfilled access. This is because of the general possibility of turning linguistic into proper, fulfilling access by taking appropriate steps (e.g. by travelling to Smolensk and picking out the tallest male) either actually or in thought. ${ }^{38}$ In some cases fully adequate access will, of course, be 'medically' (contingently) impossible, and it will then be necessary to extend in thought our actual resources for access by means of idealising assumptions based on imaginative variation; but such an exercise is of interest only to the extent that our assumptions preserve some analogy between assumed faculties and those with which we are familiar. 'Analogous' access is possible, for example, in the case of fictional objects, for the art of the novelist is precisely to awaken our imagination in such a way that we attain a vivid intention of the characters in the novel even on the basis of the meagre symbolic resources laid down therein. ${ }^{34}$ And analogous access is possible also in the case of infinite numbers, where access is achieved when the process of counting, which gives fulfilled access to finite numbers, is extended by analogy into the transfinite. I wish to claim, however, that there are some cases where fulfilled 'target' access, conceived as the result of such a procedure of analogous extension of our known accessresources, is absolutely impossible, and that this is true precisely for the whole field of noematic entities. For there are no steps whioh can be taken to turn abstract or empty referential access to noematic entities into proper referential access. An alternative statement of this claim would be that the second-order noema of an act of reference to a first-order noematic entity can never be a fulfilled noema. This dispels one important misconception of the process of reflection, according to which this process involves a special access to 'inner' entities or processes: reflection is rather a complex process of thought directed to referential entities, for example: to past events and to the referential products of earlier cognitive experiences such as linguistically expressed thoughts.

Thus we cannot, to use Hume's phrase, ${ }^{35}$ 'turn our eyeballs in our sockets' and somehow 'see' the noemata of our acts; and it is likewise impossible, as Hume recognised, to turn 'noematic' access to our 'selves' into full referential access. For

when I enter most intimately into what I call myself, I always stumble on some particular perception or other... I never can catch myself at any time without a perception, and never can observe anything but the perception. 36 
It is no accident that exactly parallel considerations apply equally well to noemata as to selvesi.e. in Husserl's terms, to transcendental egos for noemata and selves are two sides of the same coin: the self is that which actualises noematic entities and which is exhausted, ontologically, in its actualisation of such entities.

The claim that noematic entities are never 'properly' accessible as referents, conflicts with some of Husserl's own accounts of the status of noemata, in which Husserl claims that the latter are accessible via a specific method, the 'phenomenological reduction'. This method Husserl characterised as allowing the 'breakthrough' into a whole new realm of scientific exploration: the realm of noemata. It is possible to argue, however, that despite some grandiose programmatic accounts of his philosophical method, Husserl obtains his sharpest and most important results through a complex, but quite familiar heuristic of reflection, conjecture, deduction, correction, and so on, and that these results never depend upon a fulfilled, face-to-face access to noematic entities achieved by means of some special method. Indeed 'noematic' access to such entities, that is to say, simple actualisation in thought, is all that is required. ${ }^{57}$

Frege's own work in ontology falls into two sections belonging to two different periods in his philosophical career. The first and most familiar ontological theory developed by Frege, a theory which concerns the distinction between objects and functions, belongs to Frege's early writings in this field 38 and serves as a presupposition of all his later works. The second theory, which appears in a developed form in Frege's "Logical Investigations", 39 concerns the opposition between subjective and objective entities. We shall have occasion to return to this later theory below, meanwhile we can investigate the relations which exist between Frege's object-function ontology and the objectnoema theory sketched above.

Frege held that entities could be divided into two categories:

(i) objects: the referents of 'complete' (i.e. singu. lar denoting) expressions; (ii) functions: the referents of 'incomplete' expres. sions,

where concepts are distinguished as a special category within (ii). Paradigm members of this category are mathematical functions such as the cosine or the square root function. But Frege held that, since expressions such as 'capital city of' operate just as do mathematical functional expressions in that when applied to one name (say 'Denmark') they yield a second name ('Copenhagen'), these expressions also must be ascribed entities, functional entities, as their referents. Having taken this step, Frege effected a further generalisation, by regarding all 'incomplete' expressions as functional in precisely this sense. 'Is a planet', for example, Frege viewed as denoting a function from objects to truth-values; the value of this function for the argument Venus will be truth, and for the argument Napoleon falsehood. 'Concept' was the term which Frege selected to denote functions of this sort. 40

There is something unsettling in Frege's view of concepts as the referents of predicative expressions. It has been suggested by Dummett that the peculiarity may arise for linguistic reasons: 'In English,' though not, he suggests in Frege's German, "we should naturally interpret "concept" as being that which a person possesses when he grasps the sense of a word or range of words.' ${ }^{\prime} 1$ Dummett concludes that a more natural interpretation of Frege's 'Begriff' may be 'property' rather than 'concept', and this is supported by passages where Frege tells us that he calls the concepts under which an object falls its properties'. 49 But even then it is unnatural to say that an incomplete expression such as 'is a horse' refers to the property of being a horse. This unnaturalness arises in virtue of our tacit acceptance of the principle that signs refer only in so far as they are intended as referring, one consequence of which is that it becomes impossible to justify the claim that incomplete expressions refer at all: not 'cosine( )' but 'the cosine function' is the expression which, on this view, is to be taken as referring to the cosine function as a mathematical entity. Incomplete expressions do however possess senses (meanings), and we can even identify the category of concepts' (including, now, functional and 
relational concepts) with the category of senses, of incomplete expressions. 43 Now the ontological demarcation line between noematic and nonnoematic entities, and the new 'Fregean' category of objects will come to coincide - in part - with our 'Husserlian' category of object-in-general, whilst 'Frege' 's category of concepts will overlap with the 'Husserlian' meaning-in-general category. The modified Fregean division rests not on differences in the logico-grammatical category of corresponding 'referring' expressions, but rather on a difference in mode of relation between expressions and corresponding entities. This can either be a referential relation, corresponding, in the Husserlian frame, to 'target' access, or it can be the relation of an expression to its sense, corresponding to 'noematic' access. But here we must take account of the fact, which we have so often had occasion to note, that senses (and in particular, concepts) can in certain cases play the role of referents. For otherwise we should find that our theory was subject to paradoxes of the kind which beset Frege's original theory within which every singular denoting expression denotes an object. Under these conditions it becomes impossible to employ such an expression to refer to a concept or relation, for even an expression such as 'the concept horse' denotes an object and not a concept.44 Frege is therefore forced to acknowledge new ontological categories containing what, following Wells, 45 we can call 'concept correlates', 'relation correlates', and 'function correlates',- the abstract objects which result when we impose the alien form of objecthood upon concepts, relations and functions. Such correlates, Frege suggests, $4^{6}$ are to 'represent' concepts, relations and functions within the domain of objects. Now whilst correlates are introduced into Frege's theory for merely formal reasons, namely as a means of meeting what we shall see is an easily removable paradox, there are many areas of philosophical interest where the introduction of correlates has a real theoretical motivation. The typical analytic philosophical approach to noematic entities, for example, is to search for ways of identifying these as particular abstract objects: senses, for example, are identified as the equivalence classes of synonymous expressions. 47 From a phenomenological point of view it is clear that the latter must be distinguished, rather, as the sense correlates of the corresponding (noematic) senses. This is an example of covert introduction of correlates within a theory. As an interesting case of overt introduction of correlates we can instance the attempt by Löwenheim 48 to produce a foundational theory for mathematics within the Peirce-Schröder logical tradition, a tradition to which, in their early periods, not only Husserl,49 but also Whitehead and Skolem belonged. The central principle of Schröderian logic is that no difference is recognised, within the symbolism, between properties, concepts and sets. Thus ' $T$ has the property $a$ ', ' $T$ falls under the concept $a$ ', ' $T$ belongs to the set $a$ ', ' $T$ is $a$ ', are all represented, in Schröderian, by means of one and the same expression. Schröder himself has taken the notion of set (Umfang) as primary in the interpretation of his symbolism, but Husserl put forward an alternative theory in which the concept (Inhalt) is taken as primary. ${ }^{50}$ Sets thus become assimilated to concepts, and set-membership is identified as the relation of an object to a concept under which it falls. But now all sets are seen as belonging to the category of meanings, all elements of sets as belonging to the category of objects. We can already see how, on this interpretation, the paradoxes of set theory (such as Russell's paradox of the set of all sets which are not members of themselves) can be avoided, for sets of sets of any kind come to be excluded within Schröderian logic. Such a restriction on setformation is normally taken to imply an unacceptable loss of power in the resultant mathematical machinery, but Löwenheim suggests a way in which the whole of traditional mathematics, including Cantor's set theory, can be given a Schöderian form: die Mathematik, Löwenheim claims, 'lässt sich verschrödern'. ${ }^{51}$ Löwenheim's method is to construct a Schröderian model for classical set theory by defining, for each set which we wish to be treated as an element in a second set, a proxy object which is to represent the former in the latter. Such proxies can now, of course, be identified as set correlates.

Thus the scope of Frege's theory of correlates becomes significantly expanded when applied within the Husserlian framework, for now we must recognise not only concept, relation and function correlates, but also sense correlates, noema correlates, proposition correlates, even 
whole theory correlates. Within this framework also the paradoxical consequences which motivated Frege's original theory are easily avoided, for it is not the logico-grammatical form, but the intention of a given referring expression ${ }^{52}$ which determines the ontological category of its referent. Thus instead of paradoxes we have only either correct or incorrect intentions of relevant expressions: if, say, an analytic philosopher $A$ uses the expression 'the sense of the expression "horse" ' to refer to an abstract object, say a particular equivalence class, then, given the noematic view of senses, it will follow that what is denoted by A's intention of this expression is not a sense, but a sense correlate; clearly however a second subject, say a phenomenologist $B$, may use the same expression in such a way that it does refer to a sense.

The above remarks imply the recognition of two distinct species of abstraction. Not only do we have the 'noematic' abstraction which gives (noematic) access to, say, a particular 'objective' linguistic meaning by abstracting from the range of partial 'subjective' meanings associated with a given expression; we also have a second process of 'referentialising abstraction' by means of which sense or noema correlates are generated, i.e. when, against some particular background theory, we impose the alien form of objecthood upon some noematic entity. Much confusion in the theory of abstraction can be attributed to the failure to recognise the difference between these two abstractional axes.

In his later ontological works Frege puts forward an ontology based on a division of entities into three realms ${ }^{53}$ which, following Thiel, 54 we can express as follows:

1. the subjective real realm, consisting of ideas and combinations of ideas considered as private mental images,

2. the objective non-real realm, consisting of platonistically conceived thoughts and senses in general, and of all the 'ideal' objects of logic and mathematics,

3. the objective real realm, consisting of material objects, events, processes, etc.
The semantic dimension of Frege's philosophy can also be expressed in terms of a trichotomy, namely
a. sign
b. sense
c. reference.

There is a consistent tendency on Frege's part to 'confuse' these two dimensions, a tendency which has been ably documented by Thiel in his important book on Frege's semantics. ${ }^{55}$ Theil claims, as we have seen, that any ontological interpretation of the semantic trichotomy must break down, in view of the fact that not only signs but also senses may play the role of referent. But that Frege himself did not draw Thiel's absolute dividing line between semantics and ontology is seen by his deliberate adoption of the terminology of 'realms' in semantics.56 Thiel is able to show how Frege's talk of realms involves the covert attempt to identify the middle term $b$. of the semantic scheme, with the middle ontological category (the objective non-real) distinguished above, for example where Frege tells us, in his paper on the sense-reference theory that

a truth value cannot be part of a thought, any more than, say, the Sun can, for it is not a sense but an object. $5 \gamma$

In terms of our Husserlian framework such passages can be interpreted as revealing that Frege was in possession of the grain of ontological truth which they can be shown to express; but Frege's insights in this field are in danger of being lost in the rudimentary ontological scheme of

1. the subjective real

2. the objective non-real

3. the objective real,

which is in urgent need of refinement.

Frege's conception of a 'subjective real' realm seems to have been motivated by an inadequate philosophy of mind on Frege's part, based on

A false dichotomy between mental images as subjective and incommunicable, [and] senses as objective and communicable. 58 
Frege makes great play with the notion of mental image, conceived as an entity in the target position for an act. ${ }^{59}$ Thus it may be suggested that for Frege an act of hallucination of, say, a unicorn grazing on the lawn, would be analysed as an act having as its object a private unicorn image; we have already seen, however, that this type of non-veridical act is distinguished precisely by the absence of any object. Mental images are also clearly excluded from playing the role of object for veridical acts, where it is the transcendent object of the act which holds the target position. Thus we can conclude that mental images are noematic entities. 60 It is of course possible to isolate those aspects of an act which are dependent upon an individual psyche, by treating the act as belonging to the subjectmatter of empirical psychology; but then the act ceases to be 'subjective' in any special sense: it falls within the scope of an objective science, and thus belongs to the realm of the 'objective real' as Frege conceived it.

Inherently 'subjective' entities, therefore are excluded from the category of objects, and also from the category of noematic entities, all the members of which are at once subjective, in that they are actualised by some particular subject, and objective in regard to their content. Thus Frege's 1 st realm, the realm of the subjective real, falls outside the domain of 'ontology' as here advanced. Frege's 3rd realm, which is determined by a hardheaded conception of the 'objective real world' as this is presented, on a broad front, by the various natural sciences, a conception shared by both Frege and Ingarden, can, however, be accepted as it stands. Hence much comes to depend upon the realm of the objective 'non-real' in the Fregean framework.

It must first of all be recognised that, in allowing within the same ontological category not only 'thoughts' and senses in general, but also numbers and truth values conceived as objects, Frege reveals that the ontological promise of his early sense-reference theory has been unfulfilled. Frege's ontology can be put to rights, however, if we distinguish the various components which make up the hybrid Fregean category of the objective non-real. Most importantly we can distinguish a category of subjective-objective noematic entities, a generalisation of the realm of senses' as conceived by Frege. 61 We can also distinguish various possible realms of non-real objects, according to the different ontologically alternative conceptions of such objects which may be adopted. Non-real objects may be either autonomous (ideal) objects, ${ }^{62}$ or intentional objects such as fictional or mythical characters. Purported intentional entities are admitted as intentional objects wherever we have adequate intersubjective access in referential acts, especially on the basis of a linguistic structure such as a work of literature. Intentional objects then have a peculiar 'double structure'63: they possess not only properties (Eigenschatten) but also an inner stock of 'characteristics' (Merkmale) which they are merely ascribed. For example, Sherlock Holmes has the properties of non-existence, of having been introduced as a fictional character by Conan Doyle, of having been, perhaps, psychoanalysed by Freud in 18-; finally he has the property of having been ascribed the characteristics of living in Baker Street, of being a detective, of having solved the case of the disappearing fan, and so on. 64 Now whilst all intentional objects have temporal properties (for they are brought into being only with the creation of, say, a literary work), not all such objects have temporally determined characteristics, for not all have been ascribed the status of being in time. I wish therefore to suggest a division of intentional objects into (i) quasi-real objects, such as the objects of fiction, and (ii) quasi-ideal objects, the clearest cases of which are peripheral mathematical objects. Logical objects such as numbers or truth values were conceived by Frege himself in a platonistic fashion, as belonging to the autonomous ideal domain. But there is an alternative to this platonist conception, which is to regard such objects as intentional creations: as the quasi-ideal (concept) correlates which result when we apply a process of referentialising abstraction to particular concepts or noemata which are logically more primitive.

Clearly the validity of such a view rests on the possibility of justifying a conception of, say, numbers, as primarily conceptual or noematic entities, and here we may appeal to certain passages in 
Husserl's Philosophie der Arithmetik where Husserl shows how such a view may be developed. The meaning of these passages has been obscured, to some extent, by the fact that Husserl uses the phrase 'the number' in two different senses: in one sense the phrase is used to denote a presentation of a particular more or less abstract numbered or numberable totality, that is of a number of acts, of a number of animals, of a number of objects, and so on, where the members of each such totality are brought together by the particular interests of the presenting subject. Each such presentation is clearly, in the terminology here advanced, a noematic entity. Only in a second, derivative sense does Husserl use this phrase to denote the referentialised arithmetical number-as-object. 65 By ignoring this and other terminological distinctions ${ }^{66}$ Frege was able to exploit such passages as:

The number owes its genesis to a certain psychic process, which joins together the objects to be counted - in this sense these objects are the carriers of the number, 67

to substantiate his erroneous conception of the Philosophie der Arithmetik as a work of naive psychologism. 68

Our full ontological scheme can now be presented as follows:

I. the noematic realm

IIa. the realm of quasi-ideal objects
IIb. the realm of autonomous ideal objects (perhaps empty)

IIIa. the realm of quasi-real objects

IIIb. the objective real realm

from which we can read off the 'realm of objects' which is dictated by the theory of existential quantification, in such a way that the ontological structure of this 'realm' is made explicit. It is seen to consist of a 'central core' of autonomous objects (with their properties and relations), which is extended by layers of intentional objects, properties and relations, projected, first of all, by mathematical and scientific theories, but then also by works of theology, of comparative mythology, of literary theory, and so on. ${ }^{69}$ To accept this as a correct ontological picture does not imply that one accepts that there is some stage at which we have an adequate conception of which objectregions constitute the autonomous 'core' and which belong merely to the theory-dependent periphery. Epistemologically speaking it will aways be the case that we have only theories and their domains of quantification. But those followers of Quine who adopt a pragmatic relativist approach to ontology on the basis of such considerations have mistakenly interpreted an epistemological factum as a principle of ontology. For a clear statement of the relation between these two disciplines 70 we must look to the Austro-German tradition in philosophy, to which both Husserl and Frege belong.

University of Sheffield 


\section{NOTES}

References fall into two sections: (i) general references, given by author and date; for these see the list of references which immediately follows these notes; (ii) references to works on the relationship between Frege and Husserl: these are given' by author and by number in the appended "Bibliography of Frege-Husserl Studies".

1. Bolzano, 1837, $\$ 173$, Berg, 1926, p. 46.

2. Dummett, 1973, p. 471.

3. Ingarden's neglected multi-volume treatise (1964/65) on The Controversy over the Existence of the World must be recognised as the Hauptwerk of this tradition. See also his 1931 and Küng 1976; for Husserl see his 1900/01 (especially Investigations II and III) and Husserl, 1913, \$ 7-17. On the opposition between traditional and 'Quinean' ontology see Thiel 1967, 270f., and Thiel, 18, p. 142.

4. Frege, 1892, pp. 57, 78; Dummett, 1973, 94-109: but compare Dummett, 633f.

5. This point is often overlooked by commentators on Frege's ontology: see Thiel, 1967, p. 274.

6. Thiel, 18., 151f, 154.

7. Frege 1918-19, passim, 1918-19a, especially p. 132. For further references see Thiel, 18., p. 150 .

8. Dummett, 1973, p. 154; compare also pp. 174, 177, 442.

9. See Angelelli, 22., particularly Chs. II and IV; on Frege's 'baroque' excesses see Dummett, 1973, pp. xxi f.

10. This point is made by Tugendhat, 1967 , p. 16 .

11. In volume I of his $1900 / 01$, the Prolegomena to Pure Logic, particularly Ch. XI; see also Investigations I, $\mathbf{V}$, and VI.

12. Husserl, $1900 / 01$, Vol. I, $₫ 62$.

13. Op. cit., $\$ 67$.

14. Op. cit., $\$ 567,68$

15. Op. cit., 67 .

16. 1900/01, Vol. I, $\$ 67$, Husserliana ed., p. 245, lines 29-33, English trans. p. 237, lines 11-7 from bottom: 'we are dealing with nothing but concepts ... [which] are independent of the particularity of any material of knowledge, and under which all the concepts and objects, propositions and states of affairs, etc., that specially appear in thought, must be ordered.' (Findlay unfortunately omits 'and objects' here.)

17. For Husserl, in effect, 'object' and 'entity' are synonymous, for although Husserl does not use the term 'entity' ('Entität'), The English word is often indispensable as a translation of Husserl's 'Gegenstand'. Husserl does employ a notion which parallels the Bolzano-Frege notion of 'object' in his occasional broad use of the term 'wirklich' to designate not merely spatio-temporal ('actual') objects but all entities 'accessible prior to the phenomenological reduction' (cf. McIntyre and Woodruff Smith, 26., p. 131, n. 11). Excluded, therefore, are all meaning-entities as here conceived.

Husserl's object-in-general/meaning-in-general dichotomy plays a crucial role in his later philosophy, especially in the fully-developed theory of the relation between logic and mathematics which is to be found in the Formal and Transcendental Logic; but the dichotomy was touched on only obliquely in Husserl's later writings: this was because, roughly, one half of the dichotomy - the category of objects-in-general - fell behind the brackets of the phenomenological reduction. 'Formal ontology' has acquired its credentials as a discipline only with the work of Ingarden (see, in particular, Vol. II/1 of his 1964/65; for a criticism of Husserl's unrefined notion of 'form' see op. cit., pp. 53, 242n.6).

18. An object is 'purely intentional' if it depends for its remaining in existence (more precisely for its retaiming what weak ontological status it has) upon acts or networks of acts of consciousness. 'Autonomous' objects, that is, either real (temporally determined) or ideal (atemporal) objects, in contrast, do not depend upon anything beyond themselves for their remaining in existence. This terminology is due to Ingarden, see especially his $1931, \$ 20$, and $1964 / 65$, Ch. IX.

19. I have argued in my paper on 'The Ontogenesis of Mathematical Objects', the case for recognising purely intentional objects within certain 'peripheral' areas of mathematics. See Smith, 1975.

20. Linguistic structures 'acquire' referents in this way only when particular conditions are satisfied, such as the conditions for reading fiction against the background of an established framework of conventions, maintained, most importantly by literary critics. (This suggests the following criterion: 'to be' in fiction, is to be the value of a variable in some true theory of literary or in some true work of literary history or literary criticism.) Expressions in isolation such as 'the golden mountain', 'the unicorn grazing on the lawn', etc., do not admit of referent-ascription; clearly this is not simply a matter of size: a novel-length aleatoric 'poem' may fail to generate referents. (See note 34 below.)

21. See e.g. Frege 1892, p. 57.

22. See Husserl, 1913, p. 304, quoted by Føllesda1, 3., p. 681.

23. See Føllesdal, 3., p. 682. 
24. Strictly speaking the noematic sense, the intended object as it is intended in the act, must be distinguished as merely one component in the full act-noema. Other components are contributed by the character of the act in question (the noema of an act carried out against a background of belief in the existence of its purported object is different from the noema of an act in which this belief is neutralised by doubt or by the kind of controlled non-belief characteristic of acts of imagination) and by the noematic 'filling' (which is distinct from although correlated with the real phenomenal filling of the act in question). The classical Husserlian theory of noemata is presented in the 1st book of his Ideas (1913), $\$ 87-135$; the best modern exposition is Føllesda1, 3. It must be stressed that there is an absolute difference in ontological structure between purely intentional objects and noemata or noematic senses. Although Ingarden does not seem to have explicitly drawn attention to the difference ( $c$. Küng, 1972, n.18) it parallels a distinction which is drawn by Ingarden between objects on the one hand and Ideas on the other $(1964 / 65$, Ch. X). Ingarden's Ideas correspond broadly to concepts regarded in a platonistic way; Küng has pointed out that 'there is a systematic relationship between Ideas and noemata which have a consistent content' (See Küng, 10., p. 21, n.16).

25. The exact converse of this claim is put forward by McIntyre and Woodruff Smith, members of the school of analytic philosophy which employs the tools of Kripke-style semantics for modal logic. McIntyre and Woodruff Smith claim, namely, that every act-noema is a potential linguistic meaning of some suitably formed expression - which parallels Frege's recognition, mentioned above, that every entity is the potential referent of some suitable expression. The authors recognise (see, in particular their papers 25., and 26.) that their claim is inadequate as it stands, particularly since it does not take account of the varying degrees of 'fulness' of act-noemata. The major objection, however, concerns the conclusion which the authors reach on the basis of their claim, namely that an adequate knowledge of act-poemata can be achieved purely by reflection on linguistic meanings, for the latter, the authors suggest, are somehow well understood, (we 'grasp them all the time', 26., p. 130). From our point of view, the McIntyre-Woodruff Smith claim represents a reduction of the less to the more obscure, for it is a reduction of immediately accessible actnoemata to the domain of objectively conceived linguistic meanings which are accessible, as we have seen, only via a sophisticated process of noematic abstraction. This work, together with that of Hintikka (see his 35, and 36) is nevertheless of great value, since it reveals the close connection between what we have called noematic entities and the intentional entities of logical semantics.

26. We shall refrain from fixing upon a corresponding term to characterise entities which belong to the category of objects; clearly neither 'objective' nor 'referential' will suffice.

27. Since noematic entities do not sustain identity criteria as these are conceived by analytic philosophers, that is to say, on the model of direct comparison of objects in the 'target' position of a single act, (see e.g. Frege, 1892, p. 60, lines 10-14), such entities elude the analytic philosophical approach to ontology. Generalised identity criteria must be developed, perhaps on the basis of modal semantics (see note 25); these must be able to take into account, in particular the 'variable determinations' which feature in the content of noemata; compare Ingarden, 1964/65, Ch. X of Vol. II/1.

28. Similar attempts to base categorial distinctions upon distinctions in mode of access were made by Ernst Mally in opposition to the approach to ontology adopted by Meinong, his philosophical mentor. See the discussion by Wolf, 1972, pp. 64-65.

29. Note that act-schemata of the type illustrated should on no account be interpreted under the assumption that any geographical contiguity need be involved between act and referent: access, we might say, is merely the reverse side of the coin to the notion or directedness.

30. Compare Küng, 10 , p. $20 f$.

31. This account of non-veridical acts was, of course, rejected by Meinong.

32. In fact we have here a potentially infinite hierarchy of noemata, noemata of noemata, etc., or senses, senses of senses, etc., a possibility which, as is pointed out by Føllesdal, 3., p. 685f, is recognised both by Frege and by Husserl. See also Thiel, 18., p. 153, and Carnap, 1947, p. 130 .

33. The distinction between proper and improper access developed here rests on Husserl's distinction, made in his Philosophie der Arithmetik (1891), p. 193ff, between eigentliche and uneigentliche Vorstellung. Compare also Russell's distinction between knowledge by acquaintance and knowledge by description.

34. Ingarden's book on The Literary Work of Art (1931) contains elaborate discussions of the conditions which must be satisfied for a linguistic structure to be 'concretisable'; see in particular $\$ 23$, and Ch. 9 .

35. Hume, Treatise, Book I, Part IV, Section VI.

36. Hume, loc. cit., my emphasis; in place of Hume's 'perception' we should use 'referent'

37. The criticism here advanced of Husserl's phenomenological reduction finds support in Ingarden's works on Husserl's philosophy, in which the unconditional acceptance of the reduction on Husserl's part is seen as a major contributing factor in the latter's drift of idealism, which Ingarden, of course, could not accept. It would be possible to develop, on the basis of Ingarden's work, a truly realist account of the nature of consciousness, which would dispense with arbitrary constructions ('transcendental egos', etc.) on which Husserl and other idealist philosophers placed so great a weight. The complexity of Ingarden's own theory is too great for discussion here, but I should like to take this opportunity to remove some imprecision in the 'terminological note' on Ingarden's theory of consciousness which I provided for the Ingarden issue (Jan. 1975 , Vol. V, No. 2, p. 74) of the present journal. Ingarden introduces the term 'soul' to designate the psychological side of man - his abilities, personality traits, etc.; 'consciousness' is then viewed as something like the surface of contact between the 'soul' and the living body, the latter being subject to causal interactions in the material world. Thus it is misleading to designate consciousness as a 'monad', as was done in my 'note'. I am grateful to Professor A. Poltawski (Cracow) for much clarification in this area; further details can be found in Ingarden, 1964/65, Ch. XVI, and in Poltawski, 1975. 
38. See Frege, 1891, 1892a, and 1904

39. See Frege, 1918-19, 1919-19a, 1923-26.

40. A similar account is given of relational expressions such as 'is taller than' which Frege identified as denoting functions from ordered pairs of objects to truth values, functions which he called 'relations'. Frege's function-theory of concepts is complicated by the need to recognise functional expressions of a higherorder, e.g. the expression 'is a function'.

41. Dummett, 1973, p. 173.

42. Frege, 1892a, p. 51.

43. That Frege was aware of the possibility of identifying concepts as the senses of predicative expressions is seen by his (hardly convincing) criticism of Husserl's theory along these lines (see Frege's letter to Husserl, May 24, 1891, Mohanty, ed., 16, p. 83ff). For a general discussion see Thiel, 18, p. 148 .

44. Similarly, within Frege's theory, the relation of being taller than is not a relation. See Frege, 1892a, pp. 45f, 50 and Angelelli, 22, Ch. 6 .

45. Wells, 1951, pp. 16-17.

46. Frege, loc. cit.

47. The best exposition which $I$ have seen of the post-Fregean theory of abstraction is to be found in Thiel, 1972. For his identification of senses with equivalence classes of synonymous expressions, see p. 40 .

48. Löwenheim, 1940.

49. Husserl's understanding of and fluency in Schröderian logic is shown by the important Louvain manuscript FI 1 of Husserl's 1908/09 lectures on formal logic; see, in particular, pp. 177-93.

50. See Husserl, 1891a, 1891b.

51. Löwenheim, op. cit., p. 2. The possibility of treating sets as meaning-entities rather than as (abstract) objects is discussed, in another context, by Angelelli, 22, pp. 211-18; cf. also Thiel, 18, pp. 65ff, and Mohanty, 15, pp. 59ff.

52. The intention of an expression is noema associated with it in a given context of use.

53. See in particular the essay on 'The Thought', Frege, 1918-19, p. 523 et passim.

54. Thiel, 18, p. 151.

55. Thiel, 18, pp. 145-54.

56. Thiel, 18, p. 150 .

57. Frege, 1892, p. 64.

58. Dummett, 1973, p. 158; for more detailed discussion of the inadequacies of Frege's philosophy of mind see op. cit., p. 84 ff.

59. See e.g. 1892 , p. $59 f, 1894$, p $329,1918-19$, pp. $521,523,530$, etc.

60. A similar conclusion is reached by Hintikka concerning the 'sense data' of Moore and Broad; see Hintikka, 34, p. 84 and the references there given. Clearly images (and also sense data) may play the role of referent for second-order veridical acts, but we can never, as it were, achieve a fulfilled image of an image.

61. Following certain suggestions in Frege's "Logical Investigations" (especially the articles on 'Negation' and on 'Compound Thoughts') we can argue that logic pertains solely to this noematic realm. The individual logical connectives, the relation of logical consequence, and the properties of completeness and consistency of a deductive system, are all defined exclusively over the field of noematic entities. Frege's 'logical objects' may threaten to upset the purity of this regime, but we shall see that there are corresponding noematic entities which can execute the functions which Frege's logical objects were intended to perform.

62. Commitment to the autonomous ideal status of mathematical objects corresponds to the adoption of a platonist philosophy of mathematics: see Smith, 1976, p. 56f.

63. Compare Ingarden, 1931, pp. 119-22, and 1964/65, Ch. IX, $₫ 47 a$.

64. Noemata, too, possess a double structure (this is recognised even by Frege for the specific case of concepts: see his 1884 , p. 64f, $1892 \mathrm{a}$, pp. 50ff); but the double structure of noemata is, as already intimated in note 25 above, of a completely different kind from that which is possessed by intentional objects.

65. Compare Husserl 1891, p. 166, lines 30-31 where a distinction is made between the (noematic) 'number as general presentation' and the (referentialised) 'number as abstractum'. Husserl's argument in this chapter is barely understandable.

66. These distinctions have been well-explored by Willard in his 31 .

67. Husserl, 1891, p. 163, my emphasis.

68. See 1891 , p. 84f, for Husserl's non-psychologistic formal-ontological conception of number; for further references compare Willard, 31, pp. 106ff.

69. This picture is elaborated in Smith, 1975, 1976.

70. See, e.g. Küng, 1976. 


\section{REFERENCES}

Works are listed according to date of original edition except where indicated. Pagination and references are, as far as possible, to current editions, the details of which have been given. Further Bibliographical information can be found in Thiel, 18, Angelelli, 22, Klemke, ed. 1968, and Küng, 1976 - here works referred to by number are from the appended bibliography of Frege-Husserl studies.

Berg, J., 1962: Bolzano's Logic, Stockholm; Almquist and Wiksell.

Bolzano, B., 1837: Wissenschaftslehre, partial English translation by R. George, Oxford: Blackwell, 1972.

Carnap, R., 1947: Meaning and Necessity, Chicago.

Dummett, M., 1973: Frege: Philosophy of Language, London: Duckworth.

Frege, G., 1884: Die Grundlagen der Arithmetik, reprinted with English translation by J. L. Austin, Oxford: Blackwell, 1950.

Frege, G., 1891: "Funktion und Begriff', English translation in Geach and Black, eds.

Frege, G., 1892: "Ueber Sinn und Bedeutung", English translation in Geach and Black, eds.

Frege, G., 1892a: "Ueber Begriff und Gegenstand", English translation in Geach and Black, eds.

Frege, G., 1894: Review of Husserl 1891, English translation in Mind, Vol. 81, 1972, pp. 321-37.

Frege, G., 1904: "Was ist eine Funktion", English translation in Geach and Black, eds.

Frege, G., 1918-19: "Der Gedanke. Eine logische Untersuchung", English translation in Geach and Black, eds.

Frege, G., 1918-19a: "Die Verneinung. Eine logische Untersuchung", English translation in Geach and Black, eds.

Frege, G., 1923-26: "Logische Untersuchungen. Dritter Teil: Gedankengefüge", English translation in Klemke, ed. 1968.

Geach, P., and Black, M., eds. 1952: Philosophical Writings of Gottlob Frege, Oxford: Blackwell.

Husserl, E., 1891: Philosophie der Arithmetik, Husserliana edition by L. Eley, Den Haag: Nijhoff, 1970.

Husserl, E., 1891a: "Der Folgerungscalcul und die Inhaltslogik", Vierteljahrsschrift für wissenschaftliche Philosophie, 15, pp. 168-89.

Husserl, E., 1891b: Review of Schröder 1890, Göttingische gelehrte Anzeigen, 243-78.

Husserl, E., 1900-01: Logische Untersuchungen, Husserliana edition of Volume I by E. Holenstein, Den Haag: Nijhoff, 1975; English translation of 2nd edition by J. N. Findlay, London: Routledge and Kegan Paul, 1970.

Husserl, E., 1908/09: "Vorlesung: Logik (Formal)", MS F I 1, Husserlarchiv, Louvain.

Husserl, E., 1913: Ideen zu einer reinen Phänomenologie und phänomenologischen Philosophie (Erstes Buch), Husserliana edition by W. Biemel, Den Haag: Nijhoff, 1950.

Ingarden, R., 1931: Das Literarische Kunstwerk, English translation by G. G. Grabowicz, Evanston: Northwestern University Press, 1973. See also review by B. Smith, Journal of the British Society for Phenomenology, VI, 1975, 141-44.

Ingarden, R., 1964/65: Der Streit um die Existenz der Welt, 3 vols., Tübingen: Niemeyer.

Klemke, E. D., ed., 1968: Essays on Frege, University of Ilinois Press.

Küng, G., 1972: "Ingarden on Language and Ontology", A nalecta Husserliana, II, 204-17.

Küng, G., 1975: "Zum Lebenswerk von Roman Ingarden: Ontologie, Erkenntnistheorie und Metaphysik," Vorträge des Internationalen Kongresses "Die Münchner Phänomenologie", Phaenomenologica Series, Den Haag: Nijhoff.

Löwenheim, L., 1940: "Einkleidung der Mathematik in Schröderschen Relativkalkul", Journal of Symbolic Logic, V, 1-15.

Poltawski, A., 1975: "Ingarden's way to realism and his idea of man", Dialectics and Humanism (Warsaw), 3 , 1975, 65-76.

Riemann, B., 1876: Gesammelte Mathematische Werke, Leipzig.

Schröder, E., 1890: Vorlesungen über die Algebra der Logik, Band I, Leipzig: Teubner.

Smith, B., 1975: "The Ontogenesis of Mathematical Objects", Journal of the British Society for Phenomenology, VI, 91-101.

Smith, B., 1976: "Historicity, Value and Mathematics", Analecta Husserliana, II, 51-71.

Thiel, C., 1967: "Entitätentafeln", in Tradition und Kritik (Zocher Festscrift), Stuttgart-Bad Canstatt: Frommann-Holzboog, 263-82.

Thiel, C., 1972: "Gottlob Frege: Die Abstraktion", Grundprobleme der grossen Philosophen: Philosophie der Gegenwart, Vol. I, ed. J. Speck, Göttingen, Vandenhoeck and Ruprecht, 9-44.

Tugendhat, E., 1967: Der Wahrheitsbegriff bei Husserl und Heidegger, Berlin: de Gruyter.

Wells, R. S., 1951: "Frege's Ontology", as reprinted in Klemke, ed. 1968.

Wolf, K., 1972: "Der Bedeutungswandel von 'Gegenstand' in der Schule Meinongs", in Jenseits von Sein und Nichtsein, R. Haller, ed., Graz, 63-68. 
A Selective Bibliography of Contemporary Frege-Husserl Studies (Authors are listed in chronological order according to the year of their first contribution tothe debate).

1. Farber, M., 1943: The Foundations of Phenomenology, New York: State University of New York Press; see also review by Church, Journal of Symbolic Logic, 9, 1944, 63-65.

2. Føllesda1, D., 1958: Husserl und Frege, Oslo: I Kommisjon Hos. H. Aschehough and Co.

3. Føllesdal, D., 1969: "Husserl's Notion of Noema", Journal of Philosophy, 66, pp. 680-87, reprinted in 29.

4. Føllesdal, D., 1972: “An Introduction to Phenomenology for Analytic Philosophers", in Contemporary Philosophy in Scandinavia, eds. R. E. Olson and A. M. Paul, Baltimore: Johns Hopkins.

5. Dreyfus, H., 1963: Husserl's Phenomenology of Perception. Dissertation, Harvard University, to be published by Northwestern University Press.

6. Dreyfus, H., 1963a: "Sinn and Intentional Object", pp. 1-17 of 5, reprinted as pp. 196-210 of 29.

7. Dreyfus, H., 1972: "The Perceptual Noema: Gurwitsch's Crucial Contribution", in Life-World and Consciousness (Gurwitsch Festschrift), ed. L. E. Embree, Evanston: Northwestern UUniversity Press.

8. Küng, G., 1963: Ontologie und Logistische Analyse der Sprache, revised English translation by E. C. M. Mays, Dordrecht: Reidel, 1967.

9. Küng, G., 1969: "The role of language in phenomenological analysis", American Philosophical Quarterly, VI, 330-34 10. Küng, G., 1972: "The world as noema and as referent", Journal of the British Society for Phenomenology,
III, 15-26.

11. Küng, G., 1972a: "Noema and Gegenstand", in Jenseits von Sein und Nichtsein, ed. R. Haller, Graz: Akademische Druck- under Verlagsanstalt.

12. Küng, G., 1973: "Husserl on Pictures and Intentional Objects", Review of Metaphysics, XXVI, 670-80.

13. Küng, G., 1975: "The phenomenological reduction as epoché and as explication", Monist, LIX, 63-80.

14. Mohanty, J. N., 1964: Edmund Husserl's Theory of Meaning, Den Haag: Nijhoff,

15. Mohanty, J. N., 1974: "Husserl and Frege: A New Look at their Relationship", Research in Phenomenology, IV, 51-62.

16. Mohanty, J. N., ed., 1974: "Frege-Husserl Correspondence", translated into English with notes, Southwestern Journal of Philosophy, 5, 83-95.

17. Mohanty, J. N., 1974a: "On Husserl's Theory of Meaning", Southwestern Journal of Philosophy, 5, 229-44.

18. Thiel, C., 1965: Sinn und Bedeutung in der Logik Gottlob Freges, pagination as for English translation: Sense and Reference in Frege's Logic, Dordrecht: Reidel, 1968.

19. Pivcevic, I., 1967: "Husserl versus Frege", Mind, 76, 155-65, a translation of extracts from Ch. VIII of Husserl 1891.

20. Pivcevic, I., 1970: Husserl and Phenomenology, London: Hutchinson.

21. Pietersma, H., 1967: "Husserl and Frege", Archiv für Geschichte der Philosophie, 49, $298-323$.

22. Angelelli, I., 1967: Studies on Frege and Traditional Philosophy, Dordrecht: Reidel.

23. Mclntyre, R., 1970: Husserl and Referentiality: The Role of the Noema as an Intensional Entity, Dissertation, Stanford University.

24. Woodruff Smith, D., 1970: Intentionality, Noemata and Individuation: The Role of Individuation in Husserl's Theory of Intentionality, Dissertation, Stanford University.

25. Mclntyre, R., and Woodruff Smith, D., 1971: "Intentionality via Intensions", Journal of Philosophy, 68, pp. 541-61.

26. McIntyre, R., and Woodruff Smith, D., 1975: "Husserl's Identification of Meaning and Noema", Monist, 54, pp. 115-32.

27. McIntyre, R., and Woodruff Smith, D. $\left(^{*}\right)$ : Intentionality via Intensions: Husserl's Phenomenology and the Semantics of Modalities, forthcoming, Synthese Library, Dordrecht: Reidel.

28. Solomon, R., 1970: "Sense and Reference: Frege and Husserl", International Philosophical Quarterly, X, reprinted in 29.

29. Solomon, R., ed., 1970: Phenomenology and Existentialism (contains reprints of 3, 6, 28) New York: Harper and Row.

30. Willard, D., 1972: “The Paradox of Logical Psychologism: Husserl's Way Out”, American Philosophical Quarterly, IX, 94-99.

31. Willard, D., 1974: “Concerning Husserl's View of Number”, Southwestern Journal of Philosophy, 5, 97109.

32. Morscher, E., 1972: “Von Bolzano zu Meinong: Zur Geschichte der logischen Realismus", in Haller, ed. Jenseits von Sein und Nichtsein, see 11.

33. Rosado Haddock, G. E., 1973: Edmund Husserls Philosophie der Logik und Mathematik im Lichte der gegenwärtigen Logik und Grundlagenforschung, Dissertation, Bonn University, 1973.

34. Aquila, R. E., 1974: "Husserl and Frege on Meaning", Journal of the History of Philosophy, 12, pp. 377-83.

35. Hintikka, J., 1975: "Die Intentionen der Intentionalität", Neue Hefte für Philosophie, VIII, pp. 65-95.

36. Hintikka, J., 1975a: The Intentions of Intentionality and other New Models for Modalities, Synthese Library, Dordrecht: Reidel, includes English original of 35.

37. Stegmüller, W., 1975: Hauptströmungen der Gegenwartsphilosophie II, Stuttgart: Kröner, 86-103.

38. Bernet, R., 1976: Phänomenologische Erkenntnistheorie und Semantik. Eine Untersuchung zu Husserls Lehre von der noematischen Intentionalität, Dissertation, Louvain.

39. Smith, B., 1976: The Ontology of Reference: Studies in Logic and Phenomenology, Dissertation, Manchester.

40. Smith, B., 1978: "Frege and Husserl: The Ontology of Reference", Journal of the British Society for Phenomenology, IX.

41. Smith, B., 1978a: “An Essay in Formal Ontology”, Grazer Philosophische Studien, IV. 